\title{
マンガン-ジルコン紫顔料を用いた釉薬の赤色発色
}

\author{
加藤昌宏・山下茂樹·高橋 実 \\ 名古屋工業大学セラミックス研究施設，507-0071 多治見市旭ケ丘 10-6-29
}

\section{Red Coloring of Glaze by Manganese-Zircon Purple Pigment}

\author{
Masahiro KATO, Shigeki YAMASHITA and Minoru TAKAHASHI \\ Ceramics Research Laboratory, Nagoya Institute of Technology, 10-6-29, Asahigaoka, Tajimi-shi, Gifu 507-0071
}

\begin{abstract}
Red coloring of glaze by mixing three kinds of zircon-based pigments was studied. The zircon-based pigments used in the glaze have chemical and thermal stabilities in comparison with other ceramic pigments. Generally, the mixture of two kinds of zircon-based pigments produces an intermediate color. From a spectroscopic point of view, it seems to be able to obtain red color by mixing purple and yellow. Therefore, we attempted to synthesize a new type of Mn-zircon purple pigment using $\mathrm{ZrO}_{2}, \mathrm{SiO}_{2}$ and $\mathrm{MnCO}_{3}$. The influence of $\mathrm{ZrO}_{2}$ to $\mathrm{SiO}_{2}$ ratio and the type of glaze on the color was analyzed spectroscopically. The color of the pigment (ZSM-50) prepared at the ratio of $\mathrm{ZrO}_{2}: \mathrm{SiO}_{2}=1: 1$ was fairly purple. It was verified by $\mathrm{X}$-ray diffraction (XRD) that the main phase of the ZSM-50 was zircon. However, the mixture of the ZSM-50 and the yellow Pr-zircon did not yield a fine red color. Hence, salmon pink Fe-zircon pigment was added as third pigment and the ratio of the three kinds of pigments on the color was examined. The reddish brown glaze, which was the most reddish color at present, could be obtained at the ratio of Mn-zircon : Pr-zircon : Fe-zircon = $8: 1: 1$.

[Received October 28, 1999; Accepted May 24, 2000]
\end{abstract}

Key-words : Red coloring, Pigment, Glaze, Manganese-zircon, Mixing, Absorbance

\section{1. 緒 言}

ジルコン $\left(\mathrm{ZrSiO}_{4}\right)$ を母結晶とした顔料は比較的新しく作ら れた顔料で，プラセオジムを着色元素としたPr-ジルコン顔料 (黄色 $)^{1)}$, バナジウムを着色元素とした V-ジルコン顔料（水 色）吕及び鉄を着色元素とした Fe-ジルコン顔料（サーモンピン ク色) ${ }^{3)}$ などがある。これらの顔料は, 陶磁器用釉薬に使用し た場合，他の顔料に比べて安定した発色が得られる．また異な る発色のジルコン顔料を混合して釉薬に使用した場合には中間 色発色する. 例えば, Pr-ジルコン顔料とV-ジルコン顔料を混 ぜ合わせた場合, 薄黄緑色の発色が得られる.

ジルコン系顔料で赤色顔料を合成することを目的として着色 元素に $\mathrm{Mn}, \mathrm{Cr}, \mathrm{Ni}$ 及び $\mathrm{Fe}$ を用いて予備実験を行ったが, 単 一の着色元素では赤色の発色は困難であることが分かった。そ こでジルコン系顔料の混色使用が可能な点に着目し, 混色によ る釉薬の赤色発色を試みた，混色による赤色発色は，黄色顔料 及びサーモンピンク色顔料と紫色顔料を組み合わせることによ り可能であることが分光反射率測定の結果から予想された. と ころが黄色顔料としてPr-ジルコン顔料, サーモンピンク色顔 料として Fe-ジルコン顔料が存在するが，紫色顔料は知られて いない。 そこで, 混合して釉薬に使用した場合, 釉薬を赤色に 発色する, 着色元素に Mn を使用しジルコン系紫色顔料合成 を試みた。 また，これらの顔料の組み合わせで, 釉薬の赤色発 色を検討した。

\section{1 試料調製}

\section{2. 実 験}

\section{1 .1 顔料合成}

原料はすべて特級試薬を用いて, 母結晶原料に $\mathrm{ZrO}_{2}, \mathrm{SiO}_{2}$, 着色元素として $\mathrm{MnCO}_{3}$, 鉱化㓮として $\mathrm{NaF}$ を使用した. 予備 実験の結果 $\mathrm{MnCO}_{3}$ の添加量は $5 \mathrm{~mol} \%$ が濃厚な紫色を発色し た. 添加量が $5 \mathrm{~mol} \%$ より少ないと発色は淡色になり, $5 \mathrm{~mol} \%$ より多いと褐色から黒色になった。また，鉱化剂の添加量は $\mathrm{NaF} 2.5 \mathrm{~mol} \%$ 以上の添加の場合が濃厚な紫色発色を示した.
過剰に NaF を加えると, 顔料は合成時に一部がガラス化し凝 集固化してしまい顔料粉末に粉䂶することが困難となった。そ こで鉱化剤の添加量を $\mathrm{NaF} 2.5 \mathrm{~mol} \%$ とした．表 1 に母結晶の $\mathrm{Zr}-\mathrm{Si}$ 比を変化させた Mn-ジルコン紫色顔料の調合比を示す.

原料粉末をジルコニア製遊星ボールミルにて $30 \mathrm{~min}$ 湿式混 合し, $110^{\circ} \mathrm{C} て ゙ 24 \mathrm{~h}$ 乾燥炬にて乾燥後, アルミナるつぼを用い 大気中 $1000^{\circ} \mathrm{C}$ で加熱， $2 \mathrm{~h}$ 保持して顔料を調製した。焼成顔料 を乳鉢で微粉砕したものを分光反射率測定及び X 線回折の試 料とした。

\section{1 .2 釉薬調製}

釉薬は石灰マグネシア釉, 石灰釉, 石灰ストロンチウム釉, 石灰バリウム釉及び石灰亜鉛釉の 5 種類のアルカリ釉を調製 した ${ }^{4)}$. 表 2 に調製した釉薬の釉式（ゼーゲル式）を示す.

釉薬調製には, 工業用特級原料の福島長石, 福島ケイ石及び ニュージーランドカオリンと特級試薬の $\mathrm{MgCO}_{3}, \mathrm{CaCO}_{3}$, $\mathrm{BaCO}_{3}, \mathrm{SrCO}_{3}$ 及び $\mathrm{ZnO}$ を用いた。顔料は釉薬に対し 10 mass\%添加し，水分量が 40 mass\% となるよう水を加え，自動 乳鉢にて混合し, 磁器タイルに施釉して $1250^{\circ} \mathrm{C}$ 酸化で焼成し た.

\section{2 測定方法}

\section{2 .1 分光反射率測定}

試料粉末の分光反射率は既報5) と同様に，また釉薬は釉面を 直接分光光度計（東京電色製，Color Analyzer TC-1800）に て測定した. 測定には D-65光源を用い, $10^{\circ}$ 視野の条件で400〜 $780 \mathrm{~nm}$ の範囲で測色した。

\subsubsection{X線回折}

粉末 X 線回折（XRD）により生成した結晶を同定した。測 定には理学電機製 Rint-2000を使用した.

\section{3. 結果及び考察}

\section{$3.1 \mathrm{Mn}$-ジルコン顔料}

顔料母結晶中の $\mathrm{ZrO}_{2}$ と $\mathrm{SiO}_{2}$ の比を変化させて, 紫色に発 色する組成を検討し, 組成変化と結晶相変化の関係を評価し 
Table 1. Starting Composition of the Mn-Zircon Pigments

\begin{tabular}{ccccc}
\hline \multirow{2}{*}{ Sample No. } & \multicolumn{4}{c}{ Components (molar ratio) } \\
\cline { 2 - 5 } & $\mathrm{ZrO}_{2}$ & $\mathrm{SiO}_{2}$ & $\mathrm{MnCO}_{3}$ & $\mathrm{NaF}$ \\
\hline ZSM-00 & 0 & 100 & 5 & 2.5 \\
ZSM-40 & 40 & 60 & 5 & 2.5 \\
ZSM-45 & 45 & 55 & 5 & 2.5 \\
ZSM-50 & 50 & 50 & 5 & 2.5 \\
ZSM-55 & 55 & 45 & 5 & 2.5 \\
ZSM-60 & 60 & 40 & 5 & 2.5 \\
ZSM-100 & 100 & 0 & 5 & 2.5 \\
\hline
\end{tabular}

Table 2. Seger Formula of the Glazes

\begin{tabular}{|c|c|c|}
\hline Glaze & \multicolumn{2}{|c|}{ Seger formula } \\
\hline \multirow{3}{*}{ Lime-Mg Glaze } & $0.35 \mathrm{KNaO}$ & \multirow{3}{*}{$0.5 \mathrm{Al}_{2} \mathrm{O}_{3} \quad 4.5 \mathrm{SiO}_{2}$} \\
\hline & $0.35 \mathrm{CaO}$ & \\
\hline & $0.30 \mathrm{MgO}$ & \\
\hline \multirow{2}{*}{ Lime Glaze } & $0.35 \mathrm{KNaO}$ & \multirow{2}{*}{$0.5 \mathrm{Al}_{2} \mathrm{O}_{3} \quad 4.5 \mathrm{SiO}_{2}$} \\
\hline & $0.65 \mathrm{CaO}$ & \\
\hline \multirow{3}{*}{ Lime-Sr Glaze } & $0.35 \mathrm{KNaO}$ & \multirow{3}{*}{$0.5 \mathrm{Al}_{2} \mathrm{O}_{3} \quad 4.5 \mathrm{SiO}_{2}$} \\
\hline & $0.35 \mathrm{CaO}$ & \\
\hline & $0.30 \mathrm{SrO}$ & \\
\hline \multirow{3}{*}{ Lime-Ba Glaze } & $0.35 \mathrm{KNaO}$ & \multirow{3}{*}{$0.5 \mathrm{Al}_{2} \mathrm{O}_{3} \quad 4.5 \mathrm{SiO}_{2}$} \\
\hline & $0.35 \mathrm{CaO}$ & \\
\hline & $0.30 \mathrm{BaO}$ & \\
\hline \multirow{3}{*}{ Lime-Zn Glaze } & $0.35 \mathrm{KNaO}$ & \multirow{3}{*}{$0.5 \mathrm{Al}_{2} \mathrm{O}_{3} \quad 4.5 \mathrm{SiO}$} \\
\hline & $0.35 \mathrm{CaO}$ & \\
\hline & $0.30 \mathrm{ZnO}$ & \\
\hline
\end{tabular}

た. 合成した顔料の吸収スペクトルを次式 $f(R)$ で評価した (図 1 $)^{6)}$.

$$
f(R)=(1-R)^{2} / 2 R \quad R: \text { 分光反射率 }
$$

表 3 に顔料の CIELAB $L^{*} a^{*} b^{*}$ を示す. 顔料母結晶の $\mathrm{ZrO}_{2}$ と $\mathrm{SiO}_{2}$ の比を変化させたところ, $\mathrm{ZrO}_{2}$ を含まない $\mathrm{ZSM}-00$ 及 びジルコンの理論比よりも $\mathrm{SiO}_{2}$ が過剩に含をれるZSM-40, ZSM-45は黒褐色に発色した. ジルンの理論組成である ZSM-50は紫色に発色した。 ZSM-55, ZSM-60は濃圧色に発 色した. $\mathrm{SiO}_{2}$ を含まない $\mathrm{ZSM}-100$ は灰色を発色した。

図 2 に顔料の XRD パターンを示す. シルコンの理論比より も $\mathrm{SiO}_{2}$ が過剩に含まれるZ ZSM-40では未反応の石英が検出さ れた. $\mathrm{ZrO}_{2}$ (単斜) が過剩に含まれる ZSM-60では未反応の $\mathrm{ZrO}_{2}$ (単斜) が確認できた. ジルコンの理論組成である ZSM50の場合はジルコンが大量に生成されたが, わずかに単斜晶 系ジルコニアが残留した.

\section{2 釉薬の発色}

次に釉薬の種類による発色の違いを検討した．図 3 に ZSM-50を 10 mass\%添加した 5 種類の釉薬の分光反射率曲線 を示す．また表 4 に釉薬の CIELAB $L^{*} a^{*} b^{*}$ を示す，石灰バリ ウム釉，石灰ストロンチウム釉及び石灰亜鉛釉では濃紫色に発 色し石灰釉及び石灰マグネシア釉では薄紫色に発色した. 図 4 に石灰バリウム釉に ZSM-40，ZSM-45，ZSM-50，ZSM-55, ZSM-60を10 mass\%添加した場合の分光反射率曲線を示す. また表 5 に CIELAB $L^{*} a^{*} b^{*}$ を示す，ZSM-40, ZSM-45を添 加した釉薬は褐色に発色した. ZSM-50を添加した釉薬は濃紫 色に発色し，ZSM-55, ZSM-60を添加した釉薬は濃灰色に発 色した. 紫色の発色の度合いは, 釉薬中の塩基成分のイオン半 径が大きくなるにつれてより濃く紫色に発色した．2 価陽イオ ンのイオン半径は $\mathrm{Mg}^{2+}(66 \mathrm{pm})<\mathrm{Zn}^{2+}(74 \mathrm{pm})<\mathrm{Ca}^{2+}(99$ $\mathrm{pm})<\mathrm{Sr}^{2+}(112 \mathrm{pm})<\mathrm{Ba}^{2+}(134 \mathrm{pm})^{7)}$ であり，これら塩基成 


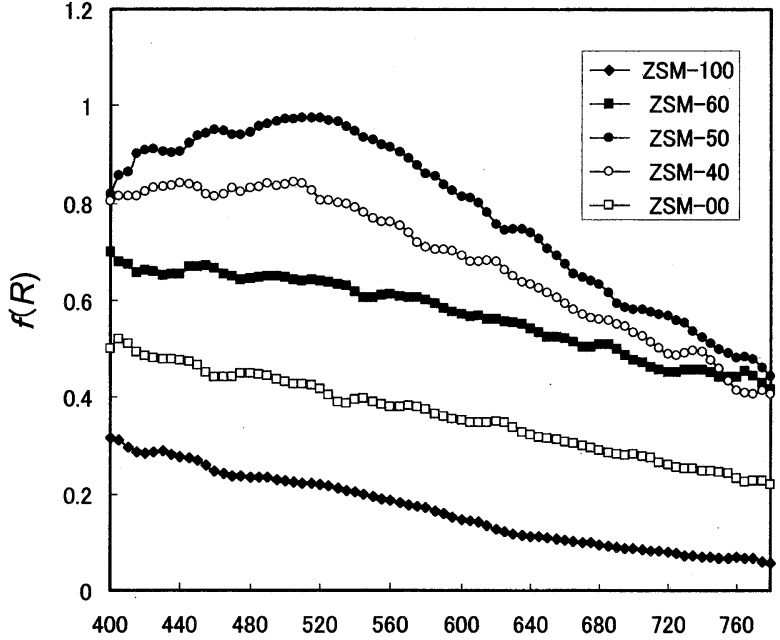

Wavelength $/ \mathrm{nm}$.

Fig. 1. Remission function $f(R)$ of Mn-zircon pigments.

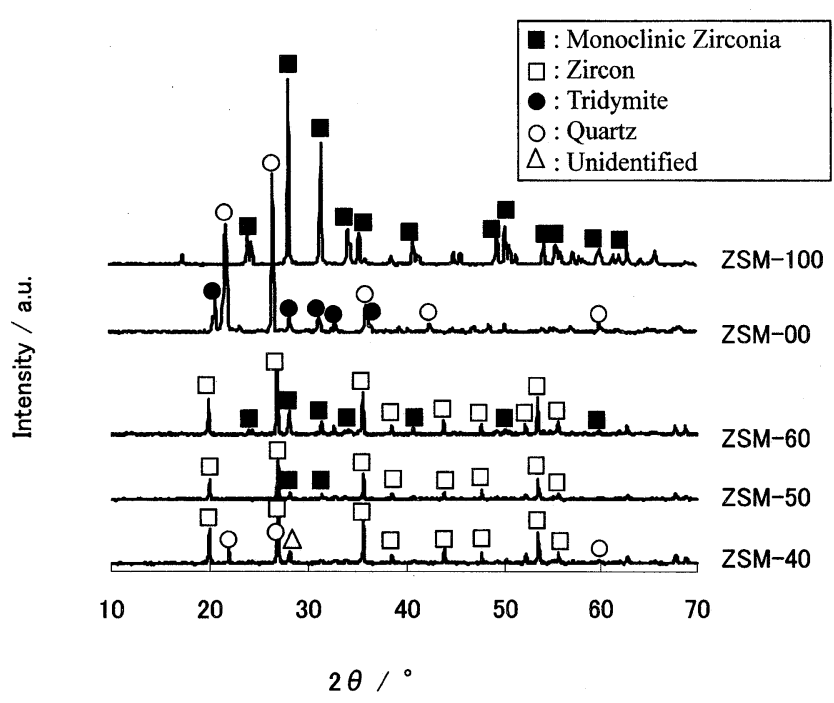

Fig. 2. XRD patterns of the Mn-zircon pigments.

分が釉薬ガラス相の網目修飾イオンとなることにより釉薬のガ ラス構造は，この順に密から疎となる8).釉薬のガラス構造が 疎であるほど顔料は釉薬中で安定に存在すると考えられる。そ の結果，釉薬中の塩基成分のイオン半径が大きくなるにつれ，

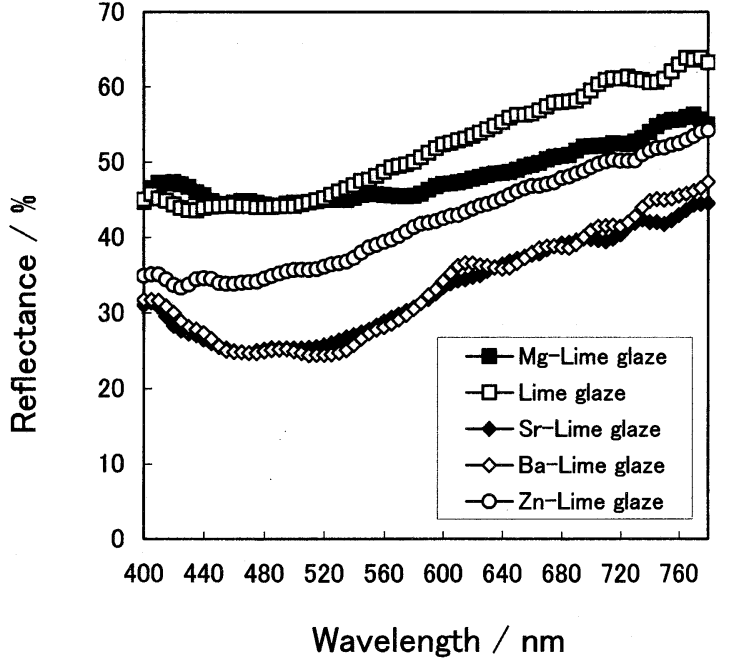

Fig. 3. Reflectance spectra of the glazes added with ZSM-50 (10 mass $\%$ ).

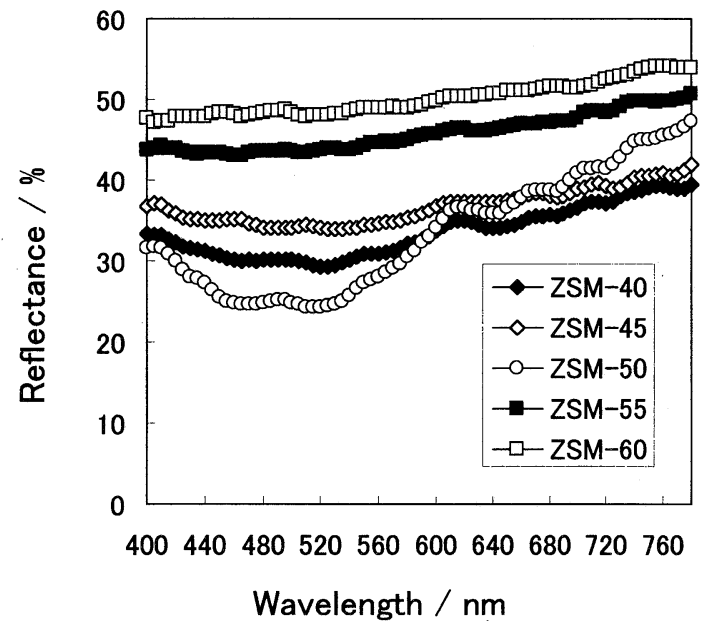

Fig. 4. Reflectance spectra of the Lime-Ba glaze added with ZSM-40, ZSM-45, ZSM-50, ZSM-55 and ZSM-60.

顔料は釉薬中で安定し, より濃く紫色に発色したと考えられ る. 石灰亜鉛釉ではイオン半径のみを考慮すると石灰マグネシ ア釉と石灰釉の間の発色が予想されるが，実際には石灰釉と石 灰ストロンチウム釉の間の発色をした.

Table 3. CIELAB $L^{*} a^{*} b^{*}$ of the Mn-Zircon Pigments

\begin{tabular}{crrrc}
\hline \multirow{2}{*}{ Pigment } & \multicolumn{3}{c}{ CIELAB } & \multirow{2}{*}{ Color } \\
\cline { 2 - 4 } & \multicolumn{1}{c}{$\mathrm{L}^{*}$} & \multicolumn{1}{c}{$\mathrm{a}^{*}$} & \multicolumn{1}{c}{$\mathrm{b}^{*}$} & \\
\hline ZSM-00 & 56.07 & 2.59 & 2.68 & Dark brown \\
ZSM-40 & 48.35 & -0.94 & -1.23 & Black \\
ZSM-45 & 50.06 & -0.61 & -0.77 & Dark purple \\
ZSM-50 & 53.56 & 4.99 & -2.83 & Dark purple \\
ZSM-55 & 52.06 & -0.78 & 0.69 & Dark gray \\
ZSM-60 & 56.58 & -1.03 & 1.28 & Dark gray \\
ZSM-100 & 78.89 & 3.10 & 5.67 & Gray \\
\hline
\end{tabular}


Table 4. CIELAB $L^{*} a^{*} b^{*}$ of the Glazes Added Mn-Zircon Pigment (ZSM-50)

\begin{tabular}{|c|c|c|c|c|}
\hline \multirow{2}{*}{ Glaze added 10 mass $\%$ of ZSM- 50} & \multicolumn{3}{|c|}{ CIELAB } & \multirow{2}{*}{ Color } \\
\hline & $\mathrm{L}^{*}$ & $\mathrm{a}^{*}$ & $\mathrm{~b}^{*}$ & \\
\hline Lime-Mg Glaze & 76.67 & 1.78 & -0.22 & Light purple \\
\hline Lime Glaze & 75.26 & 2.62 & -1.36 & Light purple \\
\hline Lime-Sr Glaze & 61.77 & 3.20 & -1.33 & Dark purple \\
\hline Lime-Ba Glaze & 57.58 & 4.44 & -1.95 & Dark purple \\
\hline Lime-Zn Glaze & 69.52 & 3.06 & -1.26 & Dark purple \\
\hline
\end{tabular}

Table 5. CIELAB $L^{*} a^{*} b^{*}$ of the Lime-Ba Glaze Added Mn-Zircon Pigments

\begin{tabular}{cccccc}
\hline \multirow{2}{*}{ Glaze } & \multirow{2}{*}{ Pigment } & \multicolumn{3}{c}{ CIELAB } & \multirow{2}{*}{ Color } \\
\cline { 2 - 5 } & & $\mathrm{L}^{*}$ & $\mathrm{a}^{*}$ & $\mathrm{~b}^{*}$ & \\
\hline \multirow{4}{*}{ Lime-Ba glaze } & ZSM-40 & 62.24 & -0.68 & -1.00 & Dark brown \\
& ZSM-45 & 60.18 & -0.57 & -0.79 & Dark brown \\
& ZSM-50 & 57.58 & 4.44 & -1.95 & Dark purple \\
& ZSM-55 & 63.11 & -0.63 & 0.55 & Dark gray \\
& ZSM-60 & 66.57 & -1.56 & 1.36 & Dark gray \\
\hline
\end{tabular}

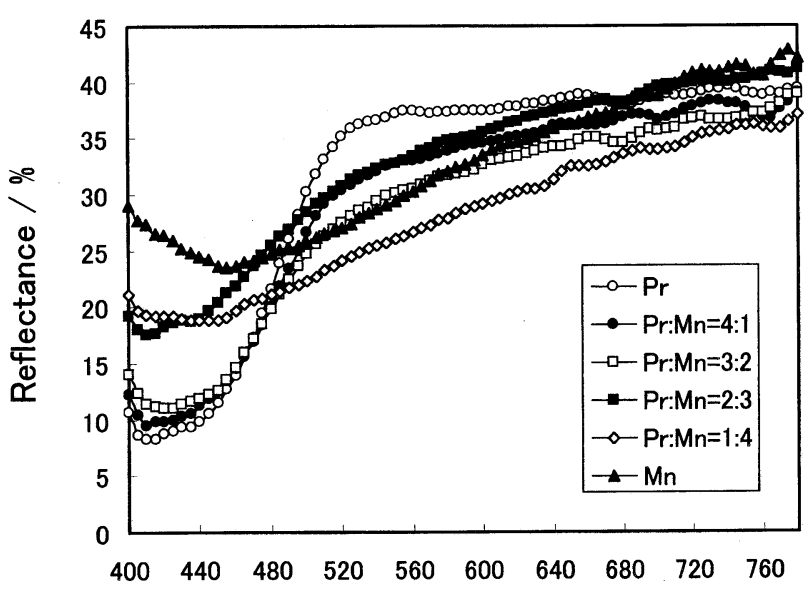

Wavelength / $\mathrm{nm}$

Fig. 5. Reflectance spectra of the glazes added with Mn-zircon pigment and Pr-zircon pigments.

\section{3 顔料の混色による釉薬の発色}

\subsubsection{Pr-ジルコン顔料との混色}

Mn-ジルコン顔料（ZSM-50）の他のジルコン顔料との混色 について検討した. 図 5 にZSM-50 と市販のPr-ジルコン顔料 を混合し，石灰バリウム釉を使用した場合の分光反射率曲線を 示す．なお釉薬には，混合顔料を 10 mass\%添加した．Mn-ジ ルコン顔料に対し Pr-ジルコン顔料の比率を $\mathrm{Mn}: \operatorname{Pr}=4: 1$, $3: 2,2: 3,1: 4$ と変化させて測定したところ $\operatorname{Pr}$ の割合が多 くなるにつれて発色は紫色, 茶色, 橙色, 黄色と変化した.

\subsubsection{Fe-ジルコン顔料との混色}

図 6 にZSM-50 と市販の Fe-ジルコン顔料を混合して釉薬に 使用した場合の分光反射率曲線を示す．Pr-ジルコン顔料との 混合の場合と同様に Mn-ジルコン顔料に対し Fe-ジルコン顔料 の比率を $\mathrm{Mn}: \mathrm{Fe}=4: 1,3: 2,2: 3,1: 4$ と変化させて測定 したところ, Feの割合が多くなるにつれて発色は紫色, 茶

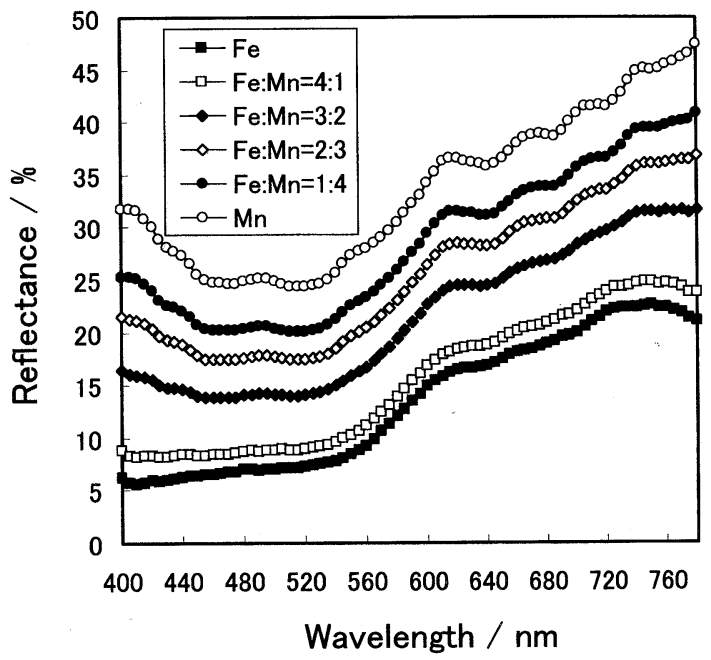

Fig. 6. Reflectance spectra of the glazes added with Mn-zircon pigments and $\mathrm{Fe}$-zircon pigments.

色，橙色，サーモンピンク色と変化した.

以上により合成した Mn-ジルコン紫色顔料が他のジルコン 系顔料と混色が可能なことが確認できた.

$3.4 \mathrm{Mn}-, \mathrm{Pr}-$ 及び Fe-ジルコン顔料の組み合わせによる赤色 発色

つぎにZSM-50 と市販のPr-ジルコン顔料及び Fe-ジルコン 顔料とを組み合わせて釉薬の赤色発色を試みた. 一般的に分光 学的に考えれば紫色と黄色の組み合わせにより赤色が発色が予 測される.しかし3.3.1項の結果により Mn-ジルコン顔料と Prジルコン顔料との組み合わせでは最も赤色に近い発色でも茶色 であり，いわゆる赤色とは異なった発色を示した．そこで更に サーモンピンクに発色する Fe-ジルコン顔料を併用することで 赤色により近い発色が得られるかを試みた. 使用した釉薬は石 灰バリウム釉で, 混合顔料が釉薬に対して10 mass\%となるよ う調製した. 図 7 に 3 種類の顔料を釉薬に混合使用した場合 
Table 6. CIELAB $L^{*} a^{*} b^{*}$ of the Glazes Added Mn-Zircon Pigment, Pr-Zircon Pigment and Fe-Zircon Pigment

\begin{tabular}{|c|c|c|c|c|c|c|c|}
\hline \multicolumn{3}{|c|}{ Pigments (mass $\%$ ) } & \multicolumn{4}{|c|}{ CIELAB } & Color \\
\hline No & Mn-Zircon & Pr-Zircon & Fe-Zircon & $\mathrm{L}^{*}$ & a* & $b^{*}$ & \\
\hline 1 & 100 & 0 & 0 & 40.28 & 15.77 & 18.63 & DP \\
\hline 2 & 90 & 10 & 0 & 51.66 & 18.56 & 16.96 & DB \\
\hline 3 & 90 & 0 & 10 & 34.84 & 17.36 & 14.07 & DB \\
\hline 4 & 80 & 20 & 0 & 55.86 & 16.19 & 9.00 & DB \\
\hline 5 & 80 & 10 & 10 & 41.85 & 20.29 & 11.18 & $\mathrm{RB}$ \\
\hline 6 & 80 & 0 & 20 & 46.03 & 21.96 & 21.21 & $\mathrm{RB}$ \\
\hline 7 & 70 & 30 & 0 & 61.55 & 19.01 & 15.81 & DY \\
\hline 8 & 70 & 20 & 10 & 58.69 & 18.65 & 19.12 & DY \\
\hline 9 & 70 & 10 & 20 & 57.05 & 13.08 & 18.36 & B \\
\hline 10 & 70 & 0 & 30 & 54.69 & 15.29 & 15.45 & B \\
\hline
\end{tabular}

DP: Dark purple DB: Dark brown RB: Red brown DY: Dark yellow B: Brown

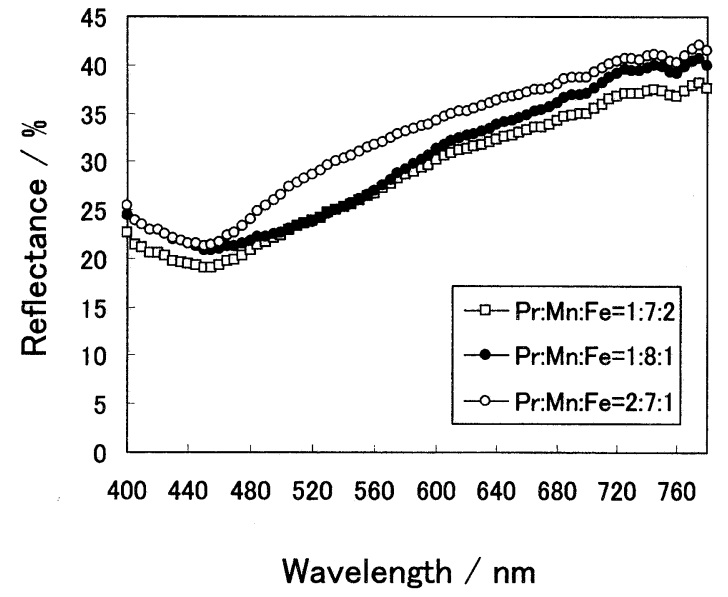

Fig. 7. Reflectance spectra of the glazes added with Mn-zircon, Pr-zircon and Fe-zircon pigments.

の分光反射率曲線を示す。をた表 6 に CIELAB $L^{*} a^{*} b^{*}$ を示 す．Mn-ジルコン顔料とPr-ジルコン顔料の組み合わせ及び $\mathrm{Mn}$-ジルコン顔料と Fe-ジルコン顔料の組み合わせでは得られ なかった赤に近い赤茶色の発色が，Mn-ジルコン顔料：Pr-ジ ルコン顔料 : Fe-ジルコン顔料 $=8: 1: 1$ の場合に得られた.
4. まとめ

$\mathrm{Mn}$-ジルコン顔料を $\mathrm{MnCO}_{3}, \mathrm{ZrO}_{2}$ 及び $\mathrm{SiO}_{2}$ を用いて合成し た結果, $\mathrm{ZrSiO}_{4}$ の理論組成で合成した場合に紫色発色するこ とが分かった. また数種の釉薬について検討した結果, 紫発色 のためには石灰バリウム釉が最適と分かった．合成した Mnジルコン紫色顔料は, 陶磁器用釉薬用として他のジルコン系顔 料と混色が可能であった。石灰バリウム釉に Mn-ジルコン顔 料：Pr-ジルコン顔料：Fe-ジルコン顔料 $=8: 1: 1$ の割合で 3 種混合することにより, 目的とする赤に近い赤茶色の発色が得 られた。

\section{文 献}

1) E. Kato, H. Takashima, Report of the National Industrial Research Institute of Nagoya, 5, 147-50 (1956) [in Japanese].

2) T. Demiray, D. K. Nath and F. A. Hummel, J. Am. Ceram. Soc., 53, 1-4 (1970).

3) R. A. Eppler, J. Am. Ceram. Soc., 62, 47-49 (1979).

4) E. Kato, "Yu Chogo no Kihon," Yogisha (1970) pp. 72-87 [in Japanese]. 加藤悦三，“釉調合の基本”，㶻技社（1970）pp. 72-87.

5) M. Kato, M. Takahashi, H. Unuma and S. Suzuki, J. Ceram. Soc. Japan, 107, 181-83 (1999).

6) S. Ishida, M. Hayashi, Y. Fujimura and K. Fujiyoshi, J. Am. Ceram. Soc., 73, 3351-55 (1990).

7) L. H. Ahrens, Geochim. Cosmochim. Acta, 2, 155-59 (1952).

8) H. Takashima, "Tojiki-Yu no Kagaku," Uchida Rokakuho (1994) pp. 101-16.

高嶋廣夫, “陶磁器釉の科学”, 内田老鶴戋 (1994) pp. 101-16. 